Article

\title{
An Automation System for Controlling Streetlights and Monitoring Objects Using Arduino
}

\author{
Zain Mumtaz ${ }^{1}$ (1), Saleem Ullah ${ }^{1}$, Zeeshan Ilyas ${ }^{1}$, Naila Aslam ${ }^{1}$, Shahid Iqbal ${ }^{2}$, Shuo Liu ${ }^{2}$, \\ Jehangir Arshad Meo ${ }^{3}$ (D) and Hamza Ahmad Madni 2,4,*(D) \\ 1 Department of Computer Science, Khwaja Fareed University of Engineering and Information Technology, \\ Rahim Yar Khan 64200, Pakistan; zainmumtaz007@gmail.com (Z.M.); saleem.ullah@kfueit.edu.pk (S.U.); \\ zeeshanilyas002@gmail.com (Z.I.); nailaaslam163@gmail.com (N.A.) \\ 2 State Key Laboratory of Millimeter Waves, Department of Radio Engineering, Southeast University, \\ Nanjing 210096, China; shahid@seu.edu.cn (S.I.); liushuo.china@seu.edu.cn (S.L.) \\ 3 Department of Electrical Engineering, COMSATS University Islamabad, Islamabad 45550, Pakistan; \\ jehangir@ciitsahiwal.edu.pk \\ 4 Department of Computer Engineering, Khwaja Fareed University of Engineering and Information \\ Technology, Rahim Yar Khan 64200, Pakistan \\ * Correspondence: 101101770@seu.edu.cn; Tel.: +86-1782-6500-615 or +92-313-4820-856
}

Received: 29 August 2018; Accepted: 18 September 2018; Published: 20 September 2018

\begin{abstract}
We present an Arduino-based automation system to control the streetlights based on solar rays and object's detection. We aim to design various systems to achieve the desired operations, which no longer require time-consuming manual switching of the streetlights. The proposed work is accomplished by using an Arduino microcontroller, a light dependent resistor (LDR) and infrared-sensors while, two main contributions are presented in this work. Firstly, we show that the streetlights can be controlled based on the night and object's detection. In which the streetlights automatically turn to DIM state at night-time and turn to HIGH state on object's detection, while during day-time the streetlights will remain OFF. Secondly, the proposed automated system is further extended to skip the DIM condition at night time, and streetlights turn ON based on the objects' detection only. In addition, an automatic door system is introduced to improve the safety measurements, and most importantly, a counter is set that will count the number of objects passed through the road. The proposed systems are designed at lab-scale prototype to experimentally validate the efficiency, reliability, and low-cost of the systems. We remark that the proposed systems can be easily tested and implemented under real conditions at large-scale in the near future, that will be useful in the future applications for automation systems and smart homes.
\end{abstract}

Keywords: Arduino; automation; energy consumption; low-cost; microcontroller; open source; streetlights; smart homes; sensors

\section{Introduction}

Automation systems [1,2] have the advantage over the manual systems because it increases the productivity, efficiency and reliability, and minimizes the usage of resources to save energy, and reduce the operating cost etc. These automation systems play an essential role in the term "smart home" [3-9] to make our daily life more comfortable, and to facilitate users from ceiling fans to ovens, and in other applications. Among all exciting applications, streetlights play a vital role in our environment and also play a critical role in providing light for safety during night-time travel. In this scenario, when the streetlights are in a working position over the whole night, which consumes much energy and reduce the lifetime of the electrical appliances such as a light-emitting diode (LED) lamp, incandescent light 
bulb, gas discharge lamp, and high-intensity discharge lamps. Especially in cities' streetlights, it is a severe power consuming factor and also the most significant energy expenses for a city. In this regard, an automation system is required to control the lights according to needs.

The traditional light system has been limited to two options: ON and OFF only, which are not efficient because these kinds of operations meant power loss due to continuing to work on maximum voltage. With the negligence of the operator or by some other technical problems, streetlights are continuously kept ' $\mathrm{ON}^{\prime}$ ', even when there is no light required on the streets and this leads to the wastage of electricity. Hence, the wastage of power from street lights is one of the noticeable power losses, but with the use of automation, it leads to many new methods of energy and money saving. In this regard, controlling the lighting system using a light dependent resistor (LDR) [10], infrared radiation (IR) obstacle avoidance sensor [11], and Arduino [12,13] together are proposed in the past [14-31]. In previous literature, the street light systems are based on LDR [17-29], and most of them are passive infrared receiver-based systems that are controlled with timers and analogue circuits. Sun tracking sensors [32,33] are also used to power OFF the streetlights by the detection of the sunlight luminance. Furthermore, streetlight control with the use of solar energy [34,35], and ZigBee based system to control streetlights [36] have also been implemented. Distinguished from turning the electricity ON/OFF, another approach is introduced to DIM (half of the maximum brightness) the light [27,31] during the hours where traffic is sparse, which might be useful for reducing the power consumption, but with the electric bulbs under a continuous usage condition.

Apart from traditional home automation, the term "internet of things" (IoT) [23,37-47] is also important for connecting electrical appliances with internet that made it feasible to remotely control items from anywhere and anytime. After the introduction of IoT, the wireless systems provided a great help for automation systems by using cloud networks and Wi-Fi etc. Similarly, many wireless systems are made by using Bluetooth and smartphones connections [48] that can only be used by a particular person, because the mobile phone is not assumed to be always at home. In addition, the recent version of Bluetooth appears to be under a good agreement for low-power home automation devices [49]. Meanwhile, a new automation system was introduced, in which both Bluetooth Low Energy (BLE) devices are used instead of smartphones, with a limited number of specifications, but with a good and secure transfer rate [50]. Most precisely, the choices of these systems are hard to implement in a real case with real roads and real streetlights, due to its very low range of wireless connectivity. To the best of our knowledge, a need still exists for the design of a sunlight-based system that supports the DIM light concept, connecting the power ON/OFF with the objects' detection, monitoring objects passing through the road, and controlling the entrance door.

In this paper, we propose and experimentally demonstrate a design to construct an automation system based on night time detection of objects. In the proposed automation system, the streetlights will be automatically turned OFF during day-time, otherwise the lights will remain DIM at night-time and turn ON (maximum brightness) at the object's detection. This work is accomplished with the proper arrangements of the microcontroller Arduino Uno, the IR obstacle avoidance sensor, LDR, and resistors. It is noticed that the DIM state in the proposed design also means the continuous working of electric appliances over the whole night. To overcome this issue, the previously designed system is further extended to construct a system based only on the detection of objects. In this regard, the streetlights will turn ON automatically based on the detection of objects, otherwise the streetlights will remain OFF. Meanwhile, an automatic door system is also introduced in this object-dependent design that will operate with a motor and an IR obstacle avoidance sensor. The motor will automatically open the door when an IR obstacle avoidance sensor detects objects in front of the door, and shut it when no objects are detected. In addition, a counter is set to count the number of objects passing through the road, which will be displayed on the serial monitor of Arduino IDE [12,13]. Thus, the proposed systems (both night and objects' detection; object-dependent) are designed and demonstrated using a lab-scale prototype to show that the proposed designs can be easily implemented in large-scale in near future. 
The rest of this paper is structured as follows. In Section 2, a concept of the automation system based on sunlight is presented with a detailed description of the electronic components used in the proposed automation system, based on night time detection of objects, and an automation system based only on the detection of objects. In addition, the experimental results for a lab-scale prototype are provided, and Section 3 concludes the paper.

\section{Materials and Methods}

For the simplicity of discussion, Figure 1 illustrates the overall working mechanism and the features of the proposed lighting concept. I/P and O/P represents the input and output, respectively. LDR first senses the intensity value of sunlight and sends it to Arduino. After receiving the data, Arduino converts it into different discrete values from 0-1023, and judges whether the received value is above the threshold level (a limit value that is set independently by the user from the range of discrete values: 0-1023); it will then be considered as day-time, and the LEDs will remain OFF; if the received value is below the threshold level, Arduino will consider it as night-time. During night-time, if the value of IR obstacle avoidance sensor is LOW and detects no object, then DIM LEDs will glow, or if the IR obstacle avoidance value is HIGH and identifies any object, then HIGH LEDs will shine. Arduino also counts the total number of objects that cross the street in the night, with the help of IR obstacle avoidance sensor, and demonstrates this to the serial monitor.

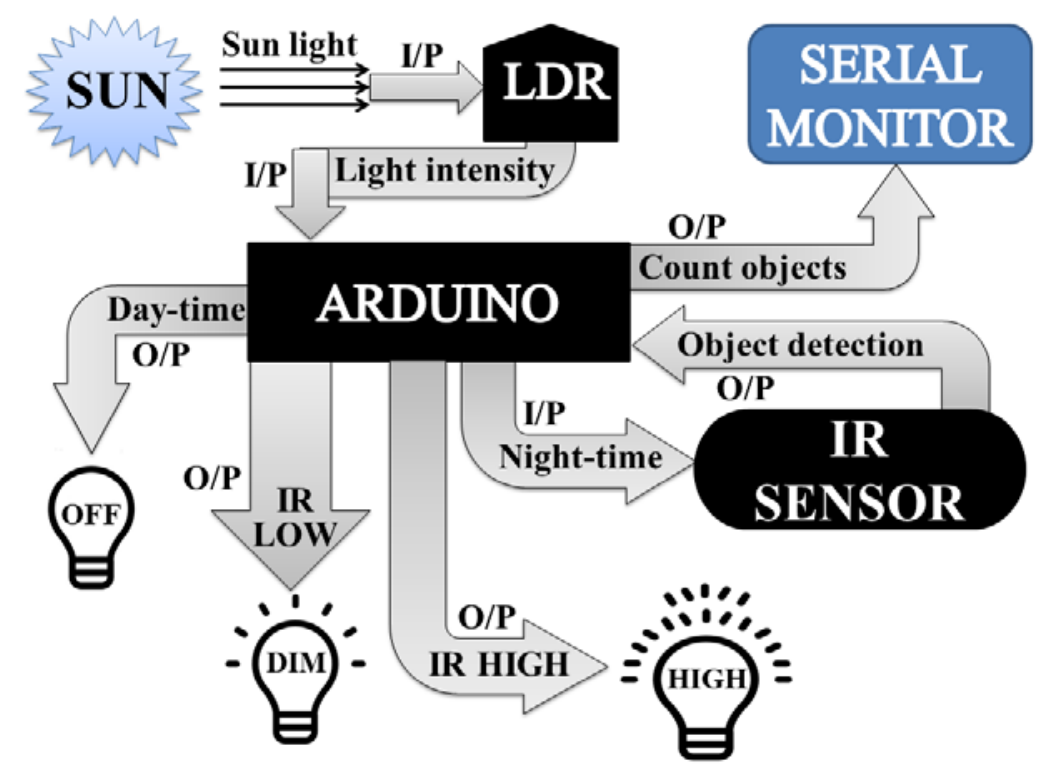

Figure 1. The architecture design of the automatic street light control system.

\subsection{Electronic Components}

Multiple electronic components are used for building electronic circuits. Our proposed circuit designs contain these components that are described in Table 1.

Table 1. Specification of electronic components used in to design the proposed system.

\begin{tabular}{cc}
\hline Components & Specifications \\
\hline IR obstacle avoidance sensor [11] & Voltage: DC 3-5 V; Range 2-30 cm; Angle: $35^{\circ}$ \\
LDR [10] & Voltage: DC 3-5 V; Diameter: $5 \mathrm{~mm}$ \\
Arduino Uno [12,13] & 22 pins; Operating voltage: 6-20 V \\
LEDs [51] & Diameter: $5 \mathrm{~mm}$; Operating voltage: $5 \mathrm{~V}$ \\
Resistors [52] & 100 ohm; 220 ohms \\
L298 Motor Module [53] & Operating voltage: 5 V; Max power: $25 \mathrm{~W}$ \\
\hline
\end{tabular}




\subsubsection{IR Obstacle Avoidance Sensor}

An obstacle avoidance sensor is a heat sensitive sensor, and it is used for the detection of motion. It consists of an infrared-transmitter, an infrared-receiver and a potentiometer for adjusting the distance [54]. Whenever an object passes in front of a sensor, the emitted rays hit the surface of an object and reflect to the receiver of the sensor, and so it will consider this as a motion [11].

\subsubsection{LDR}

The LDR [10] resistance is dependent on the amount of light impinging on it, and that resistance offered by the sensor decreases with an increase in light strength, and increases with a decrease in light intensity. LDR is used for the detection of day-time and night-time, because when sunlight falls on it, it will consider it as day-time, and when no sunlight falls on it, it will be regarded as night [55]. These are very beneficial, especially in light/dark sensor circuits, which help in automatically switching the street lights (ON/OFF).

\subsubsection{Arduino Uno}

The Arduino Uno [12,13] (licensed under a Creative Commons Attribution Share-Alike 2.5) is a microcontroller board that is based on the ATmega328 series controllers, and has an integrated development environment (IDE) for writing, compiling, and uploading codes to the microcontroller. It has 14 digital input and output pins (of which six are pulse width modulation (PWM)) and six analog inputs for communication with the electronic components such as sensors, switches, motors, and so on. It also has $16 \mathrm{MHz}$ ceramic resonators, a USB connection jack, an external power supply jack, an ICSP (in-circuit serial programmer) header, a reset button, GND pins (for grounding), and $5 \mathrm{~V}$ pin (for supplying 5 volts). Its operating voltage is $5 \mathrm{~V}$, with an input voltage 7 to $12 \mathrm{~V}$ (limit up to $20 \mathrm{~V})$.

\subsubsection{L298 Motor Module}

An L298N motor module [53] is a heavy-duty dual H-bridge controller, which is used to control the direction and speed of single or two Direct Current (DC) motors simultaneously of up to $2 \mathrm{~A}$ each, having a voltage between 5 and $35 \mathrm{~V} \mathrm{DC}$-or one stepper motor. It has four output pins for connecting the DC motors, four input pins, two Enable jumpers (one of these corresponding jumpers can be removed and connected to the PWM output for DC motor speed control) [53]. It has an onboard $5 \mathrm{~V}$ regulator, so that if the supply voltage is up to $12 \mathrm{~V}, 5 \mathrm{~V}$ power will be given from the board.

\subsection{Automation System Based on Night-Time Object Detection}

Figure 2 shows the circuit design of an automatic street light control system based on object detection using Arduino Uno, with DIM light capability. In this scenario, the lights will turn to HIGH only with the detection of an object; otherwise the lights will remain OFF at day-time, and DIM at night-time. 


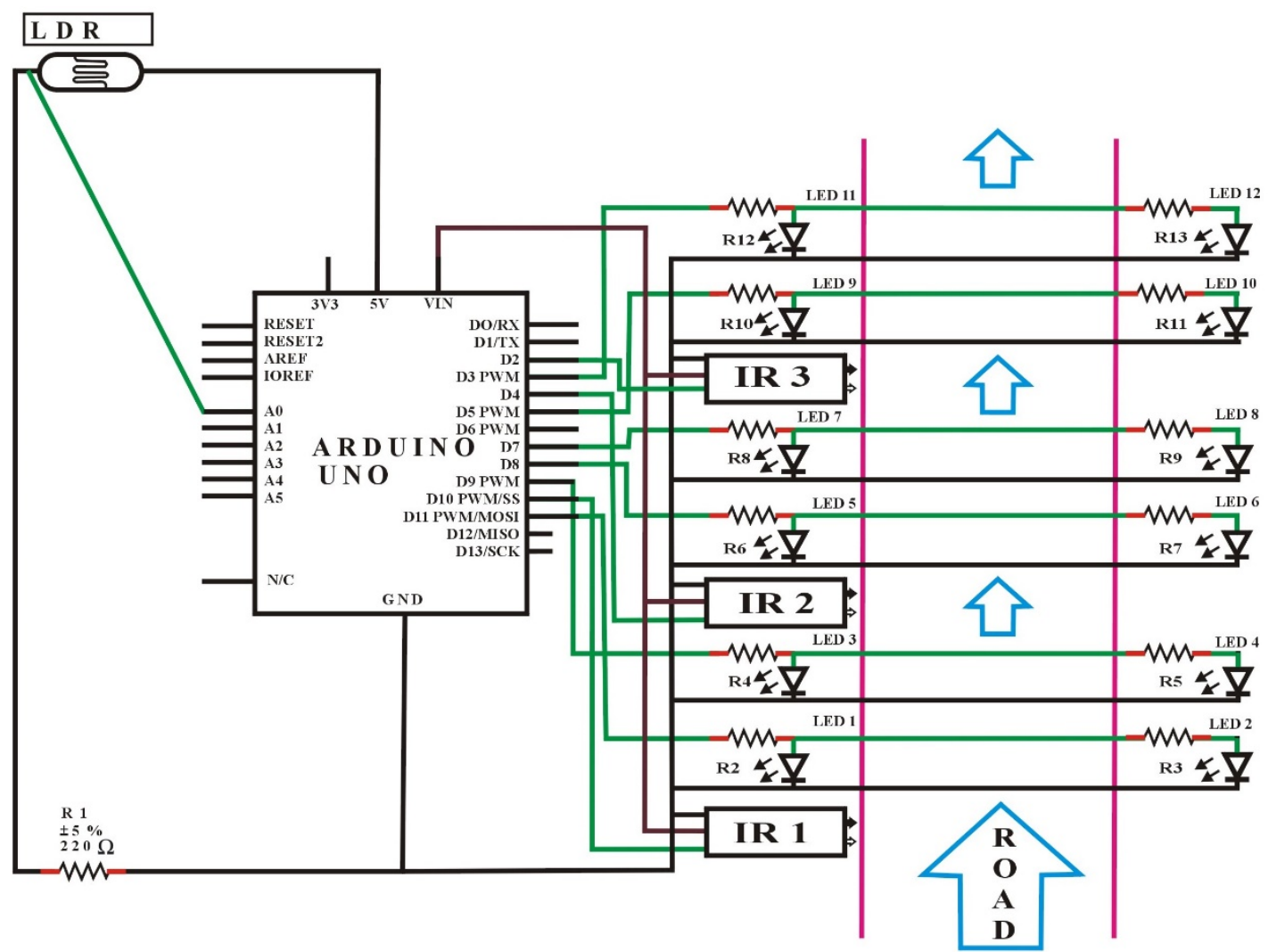

Figure 2. Circuit design of automation system based on night and objects' detection.

In this task, an LDR sensor, 12 LEDs, 13 resistors, three IR obstacle avoidance sensors, and a single Arduino Uno were used. One leg of the LDR sensor was connected to Arduino analog pin number A0, and another leg to a $5 \mathrm{~V}$ pin, and the same with a resistor to the GND port of the Arduino. Besides, the threshold value for the LDR was adjusted to 10 from the discrete values (0-1023) for understanding whether it is day or night. After that, all the positive terminals of the LED set were connected with resistors to pin numbers D11, D9, D8, D7, D5, and D3 as the outputs of the Arduino signals. Here, one set of LEDs consists of two individual LEDs. Furthermore, the GNDs of all the LEDs were connected to the GND port, as shown in the circuit diagram (Figure 2).

The OUT terminals (represented by green lines of IR1, IR2, IR3) of the IR obstacle avoidance sensors were connected to the Arduino port from pin number D10, D4, and D2, respectively, which is the input signal to the Arduino board. Similarly, the GND of all the IR obstacle avoidance sensors were connected to the GND port, and all VCC (input voltage) of the IR obstacle avoidance sensors were connected to the Arduino $5 \mathrm{~V}$ pin. Initially, the IR obstacle avoidance sensors were set to LOW (by default) at the start, if there was no motion. Meanwhile, the detailed software code for this case is given in the Figure $\mathrm{S} 1$ of supplementary materials.

\section{Results and Discussion}

In the beginning, the LDR sensor will sense the light intensity in the atmosphere at that time, and it will consequently transfer the data to Arduino, as can be seen in Figure 3. After receiving the data, Arduino will convert it into different discrete values from 0 to 1023 (in which 0 represents maximum darkness, and 1023 represents maximum brightness), and then it will adjust the output voltage accordingly from 0 to $2.5 \mathrm{~V} / 5 \mathrm{~V}$ (DIM/HIGH) depending upon the received value (0-1023) by comparing it with the threshold value. Whereas, the threshold value can be randomly chosen by the user and in this case, the threshold value is adjusted to 10 . So, the output will be $2.5 \mathrm{~V}$ in the complete darkness (night time), if the received value is less than the threshold value. As a result, DIM LEDs 
will glow that is the half of maximum brightness, and when there is completely shine (daytime), the received value will be higher than the threshold value, and the output voltage would be $0 \mathrm{~V}$, resulting the LEDs to be completely switched OFF.

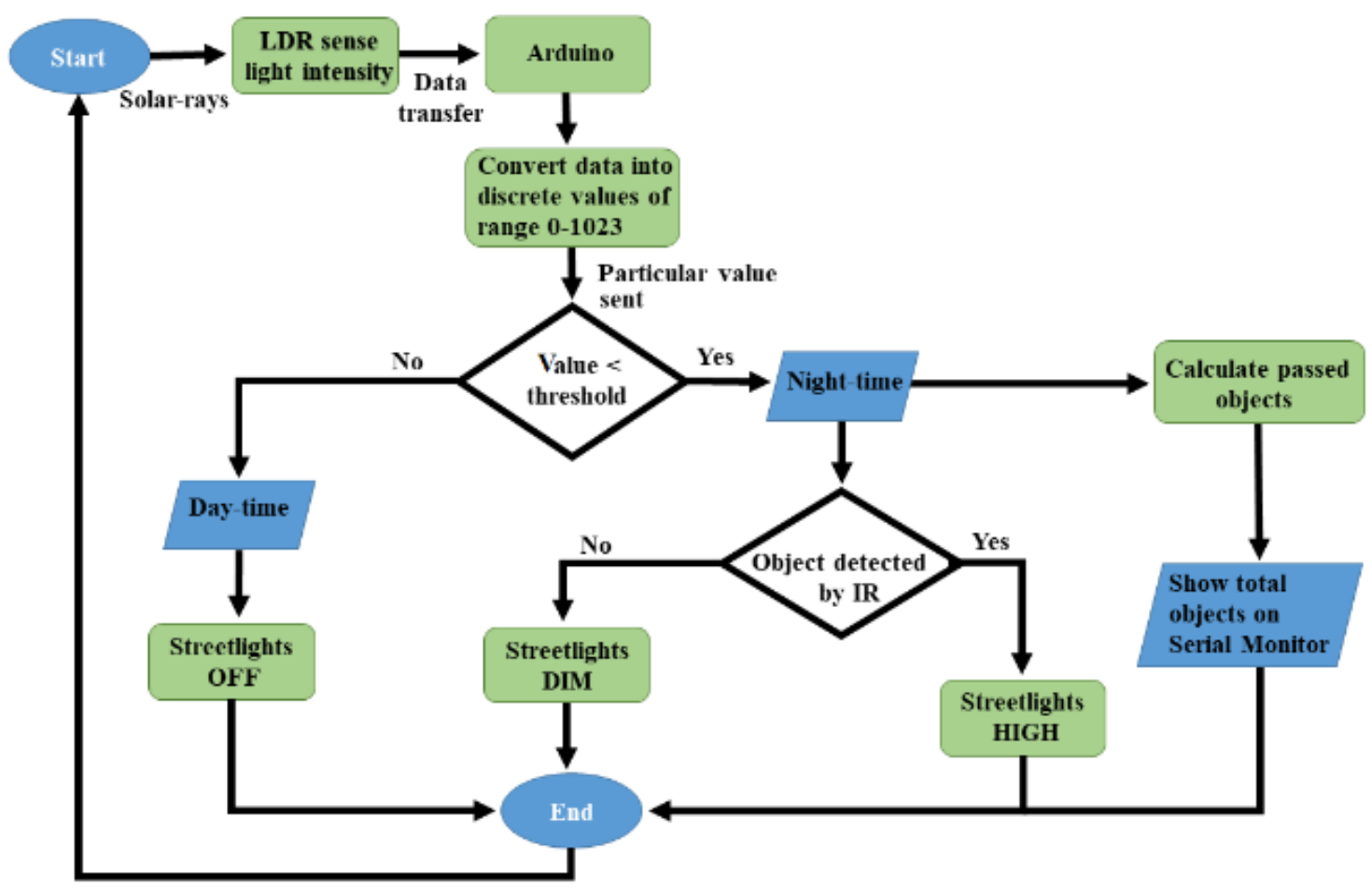

Figure 3. The flow diagram of the automation system based on night-time object detection.

Initially, the IR obstacle avoidance sensor will be LOW. So, when there is no object in front of the sensor, the IR transmitter does continuously transmit the IR light. Whenever a car or any other object blocks any of the IR obstacle avoidance sensors, then the emitted rays will reflect the IR receiver after hitting the object, then microcontroller will sense it as a motion. In simple words, when an object passed in front of the first IR obstacle avoidance sensor, the corresponding LEDs will be turned from DIM to HIGH (5 V) by the microcontroller. As the object moves forward and blocks the next IR obstacle avoidance sensor, the next three LEDs will be turned to HIGH from DIM, and the LEDs from the previous set switched to DIM from HIGH. The process continues this way for the entire IR obstacle avoidance sensors and LEDs.

Figure 4 shows the final demonstration of the proposed automatic streetlights system that turned to DIM at night-time and HIGH on vehicle movement using Arduino Uno. Figure 4a represents day-time, with no LEDs glowing after measuring the sensed intensity value of sunlight with the threshold value (10) by the LDR sensor. Figure $4 \mathrm{~b}$ shows the night-time because the sensed intensity value of sunlight by LDR was below than the threshold value (10) and there was no motion detected by any of IR obstacle avoidance sensors, so as a result, the DIM LEDs were glowing. The beauty of the proposed model can be seen in Figure 4c,d, with the motive that only those LEDs that detect the object's presence will glow brighter, and the remaining LEDs will keep maintaining their DIM state. As an example, in Figure 4c, the first set of LEDs are glowing HIGH, and remaining are in DIM mode because the sensed intensity value of sunlight by LDR is below then the threshold value, so it considered it to be night-time, and there was an object that was detected by the first IR obstacle avoidance sensor. Moreover, when the object moved to the second IR obstacle avoidance sensor, the second set of HIGH LEDs were glowing, and the first set again reverted to the DIM state (Figure 4d). These results demonstrate the efficiency of the proposed idea and give immediate validation for the 
proposed model. These kinds of application can be implemented in the headlights of objects, street lights, the parking lights of hotels, and in malls and homes.
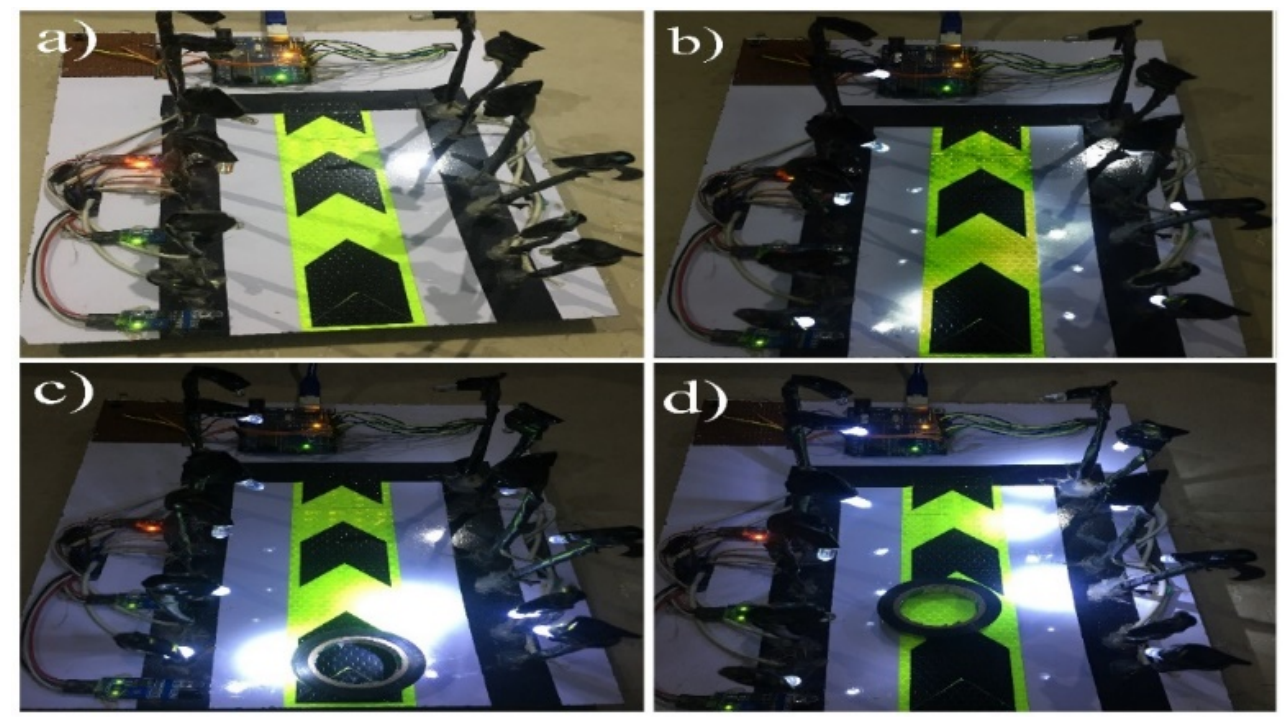

Figure 4. Result diagrams of the automatic streetlight control system that switches to DIM at night and HIGH at object detection. (a) In the day-time simulation, the LEDs are not glowing. (b) In the night-time representation, the DIM LEDs are glowing. (c) An object in front of first IR obstacle avoidance sensor; the first set of HIGH LEDs are glowing while the remainder are in DIM mode. (d) Motion in front of the second IR obstacle avoidance sensor; only the second set of LEDs are glowing HIGH, and all the others are in a DIM state.

\subsection{An Automation System Based on Object Detection}

As per our motive, the main idea of this paper is to create such an innovation for our current street light system so that the power consumption can be saved. As presented in Figure 3, when there are no objects on the road at night-time, still, the DIM light continuously glows, and it wastes energy. Thus, the task is enhanced by controlling the streetlights based on object detection only at night-time. When the object is detected at night, the LEDs will switch ON automatically; otherwise the lights will remain OFF. The circuit design at lab-scale prototype can be seen in Figure 5. Most importantly, there is also an automatic door system in this design that will operate with a motor and an IR obstacle avoidance sensor. The motor will automatically open the door when an IR obstacle avoidance sensor detects any object in front of the door, and shut it when no objects are detected. 


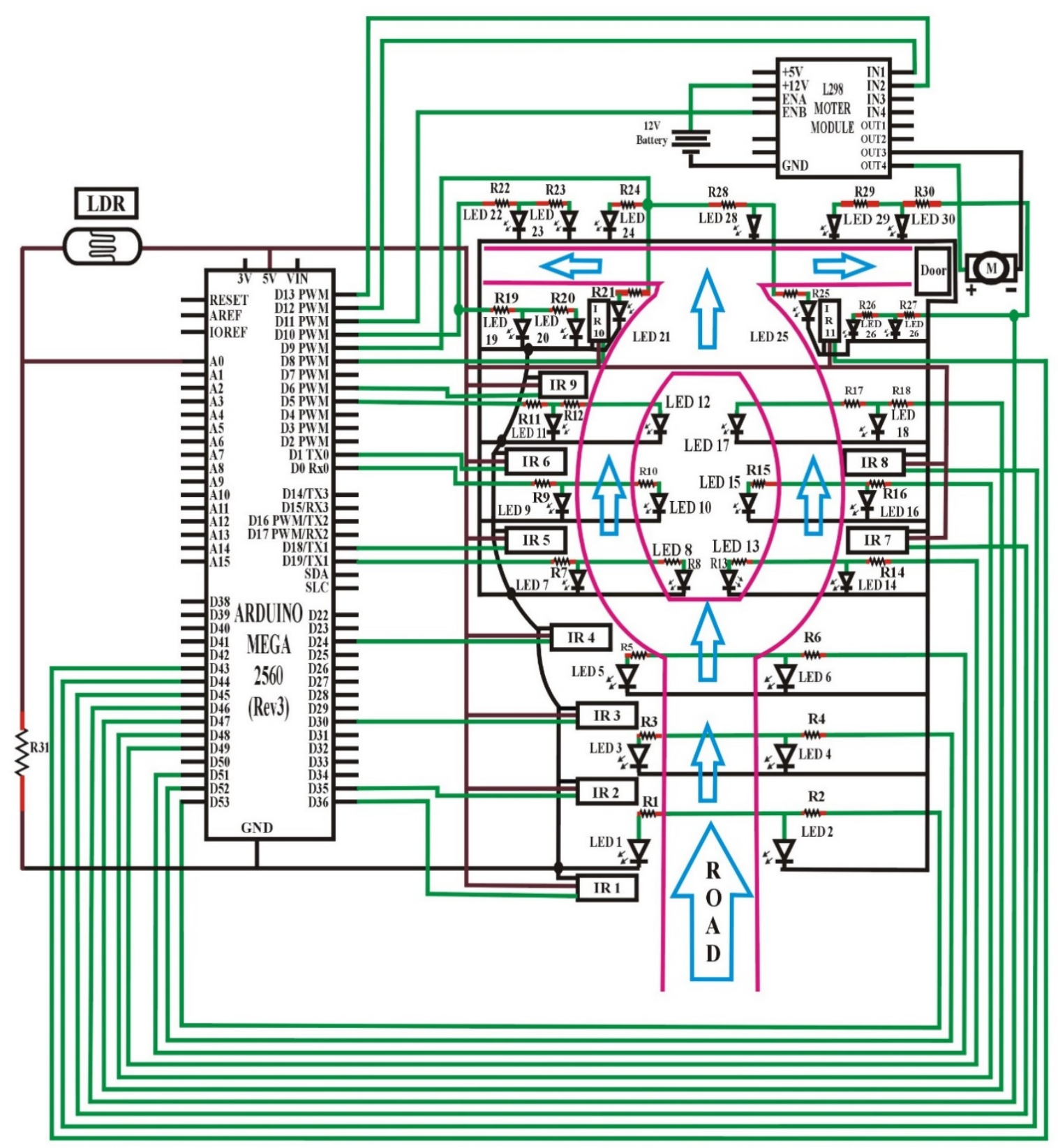

Figure 5. Circuit design of the automation system based on object detection and an automatic door system.

Figure 5 shows the circuit design of an automatic streetlight control system without DIM lights capability based on object detection using Arduino Mega [56]. In this design, an LDR sensor, 30 LEDs, 31 resistors, 11 IR obstacle avoidance sensors, a DC motor, an L298 motor module, and a single Arduino Mega were used. Hence, one leg of the LDR sensor was connected to the Arduino analog pin number $\mathrm{A} 0$, and another leg to a $5 \mathrm{~V}$ pin, and the same with a resistor to the GND port of Arduino. The threshold value was adjusted to 10 from discrete values (0-1023) for understanding whether it is day or night. All of the positive terminals of the LEDs set were connected, along with resistors to the pin number D53-D51, D19, D0, D5, D49-D47, D9, D10, and D46. In this regard, one set of LEDs consisted of two individual LEDs or more. Also, the GNDs of all the LEDs were connected to the GND port.

The OUT terminals (represented by green lines of IR1, IR2 and so on) of the IR obstacle avoidance sensors were connected to the Arduino port from pin number D36, D35, D30, D24, D18, D1, D45, D44, D6, D8, and D43 respectively, which was the input signal to the Arduino board. The GNDs of all of 
the IR obstacle avoidance sensors were connected to the GND port, and all the VCC (voltage at the common collector) of the IR obstacle avoidance sensors were directed in Arduino $5 \mathrm{~V}$ pin. Initially, the IR obstacle avoidance sensors were set to LOW (by default) at the start if there was no motion. Finally, the OUT-pin3 of the L298 motor module was connected with one side of the DC motor, and OUT-pin4 to another side. In this regard, the ENB (enable B) pin and IN (input) pins D1 and D2 were further attached to the pin numbers D11, D12, and D13 of Arduino, respectively. To supply the motor, a $+12 \mathrm{~V}$ pin was connected to the positive terminal, and GND to the negative terminal of a $12 \mathrm{~V}$ battery. The detailed software code for this case is given in Figure S2 of the supplementary materials.

Results and Discussion

The functionality of the LDR sensor remained same as described in Figure 3, this can be further seen in Figure 6. In this scenario, the output will be $0 \mathrm{~V}$ in the complete darkness (night-time) if the received value is less than the threshold value and no LEDs will glow. Similarly, during day-time, the received value was higher than the threshold value, and the output was also $0 \mathrm{~V}$, resulting in the LEDs being entirely switched OFF.

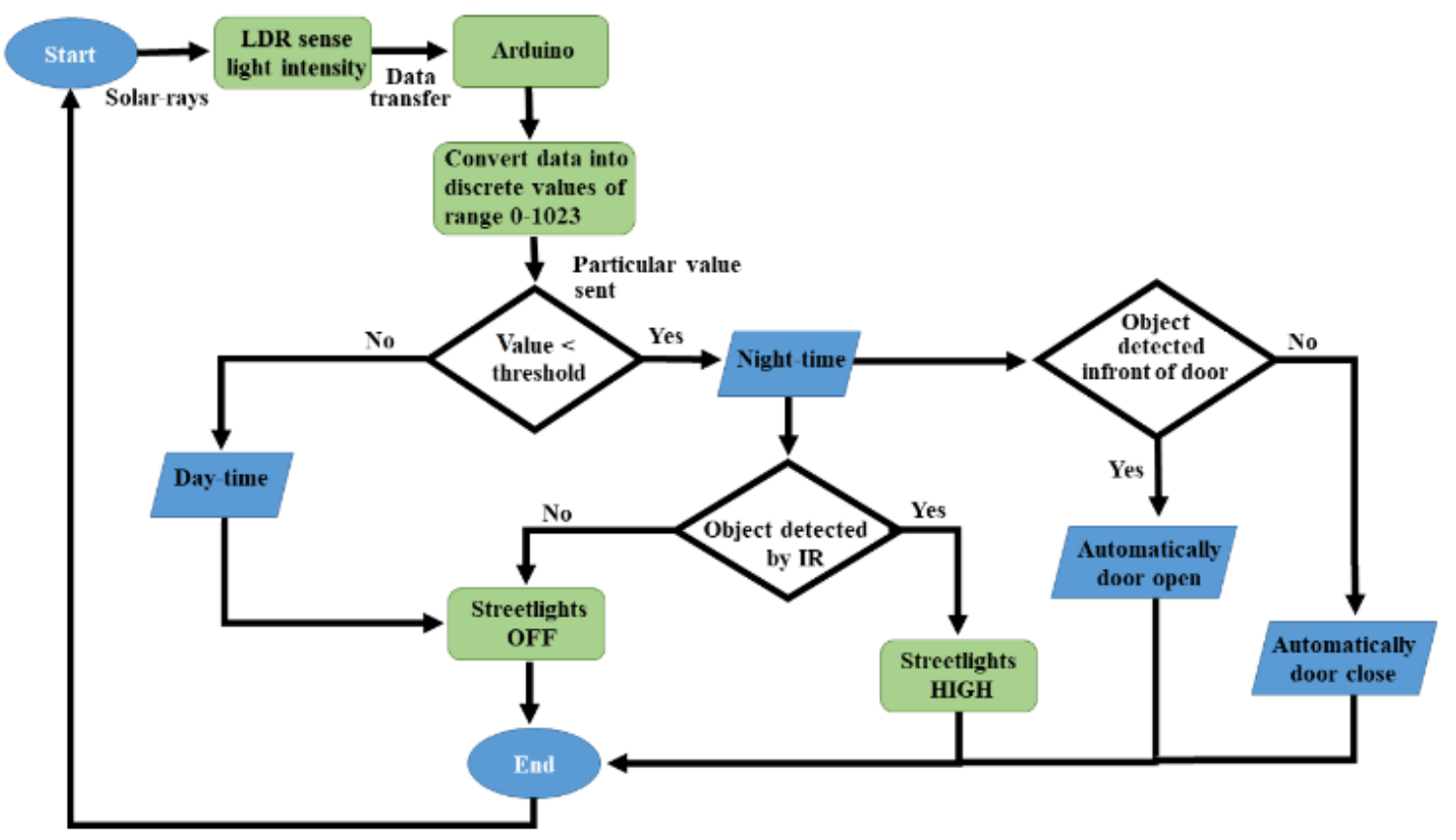

Figure 6. The flow diagram of the automation system based on object detection.

Initially, the IR obstacle avoidance sensor was LOW. Thus, when there was no object in front of the sensor, IR transmitter continuously transmitted IR rays. Whenever a car or any other object blocks any of the IR obstacle avoidance sensors, then the emitted rays will reflect the IR receiver after hitting the object, then microcontroller will sense it as a motion. In simple words, when an object passes in front of the first IR obstacle avoidance sensor, the corresponding LEDs will be turned from OFF to HIGH $(5 \mathrm{~V})$ by the microcontroller. As the object moves forward and blocks the next IR obstacle avoidance sensor, the next three LEDs will be turned to HIGH from OFF, and the LEDs from the previous set are switched to OFF from HIGH. The process continues this way for the entire set of IR obstacle avoidance sensors and LEDs.

Figure 7 shows the result diagrams of the automatic streetlights system that turn to ON/OFF only, and having an automatic door system using the Arduino Mega Microcontroller. In this way, Figure 7a is represented with no LEDs glowing after the detection of day/night-time with the LDR sensor. On the other hand, in Figure 7b, the first set of HIGH LEDs glowed in the night-time because there was a motion that was detected by the first IR obstacle avoidance sensor. Similarly, when the object moved 
forward from the second IR obstacle avoidance sensor, then the third IR obstacle avoidance sensor detected its motion and the third set of HIGH LEDs glowed, with the remaining LEDs being turned OFF completely (Figure 7c). Meanwhile, when an object was detected by the IR obstacle avoidance sensor in front of the door, it automatically opened, and the corresponding lights also turned ON, as seen in Figure 7d. Table 2 summarizes the comparison of old systems and the proposed systems as a quick review.
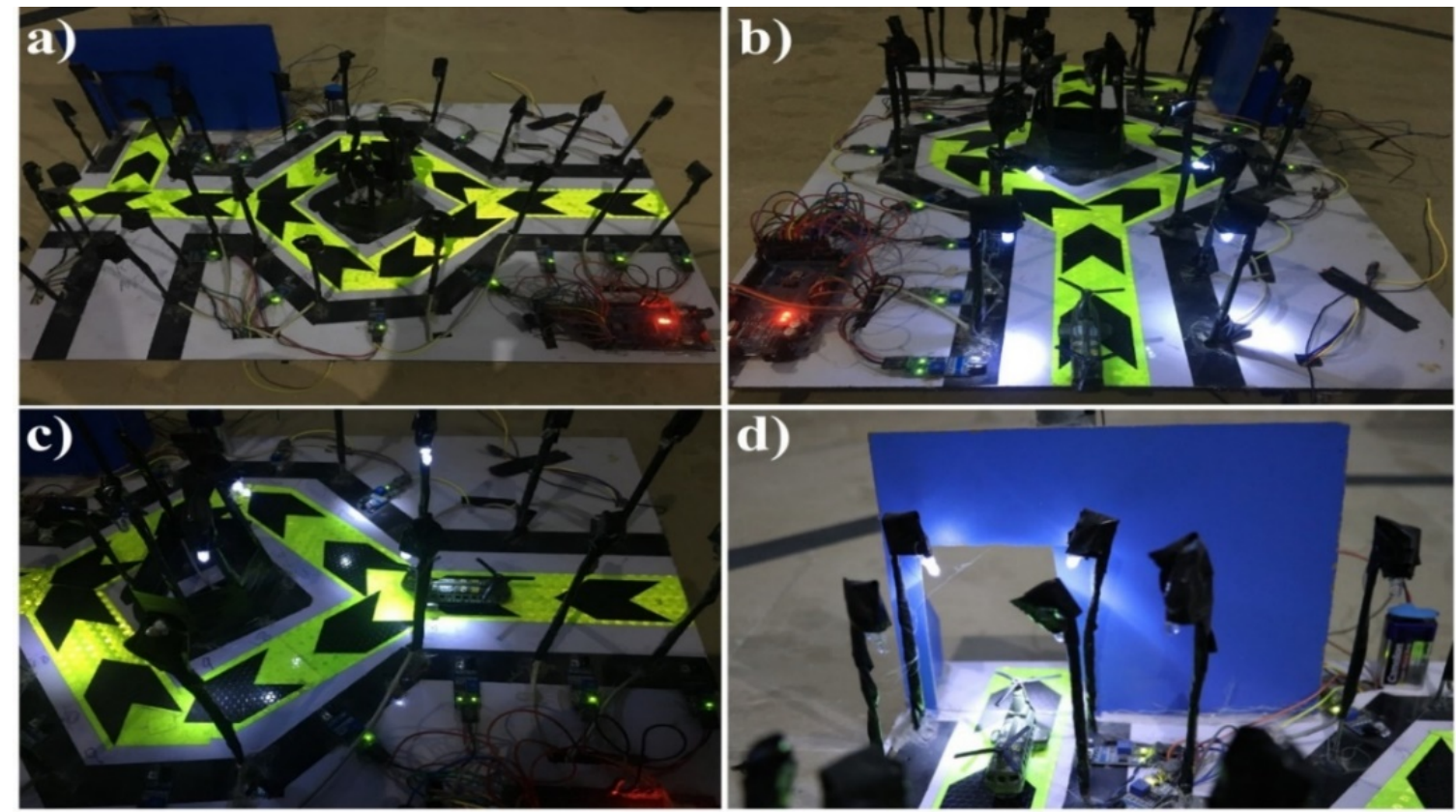

Figure 7. Result diagrams of enhanced work with an automatic door system and only an ON/OFF capability. (a) During a day/night-time simulation, the LEDs are not glowing. (b) Object in front of the first IR obstacle avoidance sensor; the HIGH LEDs are glowing. (c) Motion in front of the third IR obstacle avoidance sensor; the third set of LEDs are glowing. (d) An object detected is in front of the door, so it is automatically opened, and the relevant LEDs are glowing.

Table 2. Comparison between old systems and the proposed system.

\begin{tabular}{ccc}
\hline Functionality & Old Systems & Proposed System \\
\hline Based on Arduino & Yes & Yes \\
Operates with LDR and IR & Yes & Yes \\
DIM/FULL light capability with object detection & No & Yes \\
Displays the total number of objects passing through a road & No & Yes \\
Automatic door system & No & Yes \\
\hline
\end{tabular}

We used the Arduino-based automation systems without any wireless connectivity, in which the streetlights could be automatically controlled based on solar rays, to avoid any limitations of the specifications, wireless range, etc. In some cases, we required wireless connectivity to make the system more scalable for easy integration of new devices, and online access to the information managed by the Arduino boards to develop a user-friendly interface. In this regard, the Ethernet network can be used to access more devices from internet, and an Ethernet shield would provide easy-to-use access to these data. Meanwhile, to store and secure the acquired information of devices for further study and analysis, different kind of database could be used in our proposed designs; in fact, Arduino is easy to integrate with a number of databases. Moreover, the reported systems are presented as lab-scale prototypes, as aforementioned; therefore, the managed power can be adjusted for real-scale facilities by driving an external voltage controller. Similarly, the proposed systems can be managed for real-scale facilities by applying other technologies such as BLE [57]. For the question of wireless connectivity, the 
sensors used in Figures 2 and 6 can be replaced with different sensor types, or a combination of several types, for better results. For example, ultrasonic distance sensors [58] with the maximum range of $4 \mathrm{~m}$ range can be used; they are low cost and accurate enough for this kind of application. Alternatively, one can choose a long-range infrared-sensor [59] with a maximum range of $1.5 \mathrm{~m}$, or a combination of laser diodes [60] and photo-resistors [10,55].

It is worth noting that the objects passing through the road often contain a large number of quantities that become more difficult to monitor at night-time. Thus, on the basis of monitoring objects to improve safety measurements, the serial monitor of Arduino IDE [12,13] is further adopted and considered as an interface to count and display the number of objects passing through the road at night-time. In this regard, when any object is detected by IR sensor (Figure 3), the Arduino will consider it as a vehicle movement and will demonstrate it on the serial monitor. Figure 8 illustrates the total number of objects on the serial monitor that passed through the road at night-time.

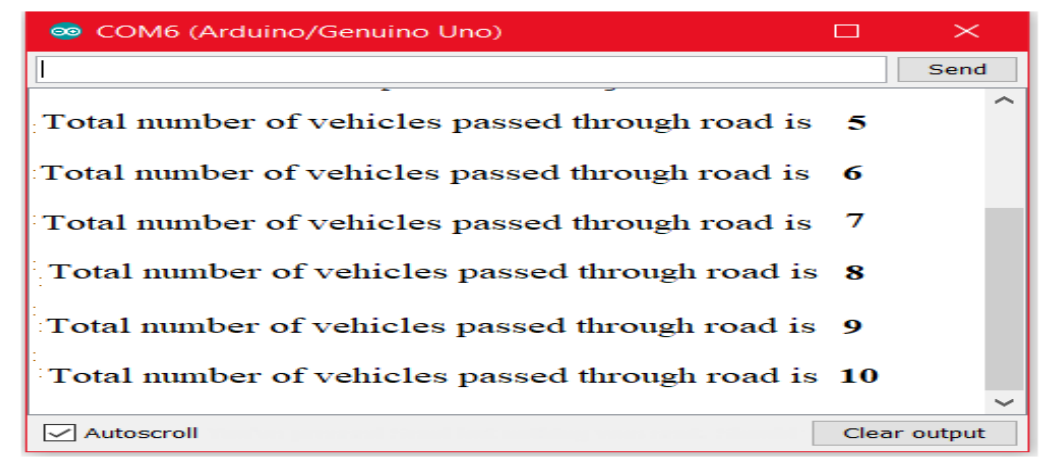

Figure 8. Serial monitor output according to traffic flow.

\section{Conclusions}

In this paper, a design scheme for controlling a streetlight system based on Arduino Uno microcontroller has been demonstrated, which can be programmed to react to events (based on night and object's detection as described above) and to cause corresponding actions. The proposed scheme provided with two operational modes, in which the first automated system is used to control the streetlights based on night (lights turn to DIM state) and object detection (lights turn to HIGH state). The same system is further extended to design a second mode that turns the streetlights $\mathrm{ON}$, based on only object's detection. Meanwhile, it is presented that the proposed automated systems have capabilities to control the status of doors (closed/opened) and monitor objects. The hardware implementations of the proposed systems were carried out at a lab-scale prototype to verify the simplicity, flexibility, reliability, specificity and low cost of the system. As a lesson learned, we found that the proposed systems can be easily tested under real conditions at large-scale in near future, and it can be easily implemented in smart cities, home automation, agriculture field monitoring, timely automated lights, parking lights of hospitals, malls, airport, universities, and industries, etc.

Supplementary Materials: The following are available online at http:/ / www.mdpi.com/1424-8220/18/10/3178/ s1, Figure S1: Circuit design of automation system based on night and objects' detection, Figure S2: Circuit design of automation system based on objects' detection and having automatic door system.

Author Contributions: All of the authors contributed in literature search, figures, study design, data collection, data analysis, data interpretation, and writing etc. Such as, Z.M. and H.A.M. designed the devices and carried out the experimental work. S.U., Z.I., S.I., S.L., N.A., J.A.M., A.M. and H.A.M. analyzed the data and interpreted the results. H.A.M. and Z.M. drafted the manuscript with the input from the others. H.A.M. supervised the project.

Funding: This work is supported by Khwaja Fareed University of Engineering and Information Technology, Rahim Yar Khan, Pakistan. H.A.M. acknowledges the support of the Postdoctoral Science Foundation of China at Southeast University, Nanjing, China, under Postdoctoral number 201557.

Acknowledgments: The authors would like to thank the Editor and the anonymous reviewers for their insightful comments and constructive suggestions that certainly improved the quality of this paper. 
Conflicts of Interest: The authors declare no conflict of interest.

\section{References}

1. Oditis, I.; Bicevskis, J. The concept of automated process control. Comput. Sci. Inf. 2010, 756, 193-203.

2. Adetiba, E.; Matthews, V.O.; Awelewa, A.A.; Samuel, I.A.; Badejo, J.A. Automatic electrical appliances control panel based on infrared and Wi-Fi: A framework for electrical energy conservation. Int. J. Sci. Eng. Res. 2011, 2, 1-7.

3. Wilson, C.; Hargreaves, T.; Hauxwell-Baldwin, R. Smart homes and their users: A systematic analysis and key challenges. Pers. Ubiquitous Comput. 2015, 19, 463-476. [CrossRef]

4. Chan, M.; Estève, D.; Escriba, C.; Campo, E. A review of smart homes: Present state and future challenges. Comput. Methods Programs Biomed. 2008, 91, 55-81. [CrossRef] [PubMed]

5. Cook, D.J. How smart is your home? Science 2012, 335, 1579-1581. [CrossRef] [PubMed]

6. Chan, M.; Campo, E.; Estève, D.; Fourniols, J.Y. Smart homes current features and future perspectives. Maturitas 2009, 64, 90-97. [CrossRef] [PubMed]

7. Ding, D.; Cooper, R.A.; Pasquina, P.F.; Fici-Pasquina, L.F. Sensor technology for smart homes. Maturitas 2011, 69, 131-136. [CrossRef] [PubMed]

8. Granzer, W.; Praus, F.; Kastner, W. Security in building automation systems. IEEE Trans. Ind. Electron. 2010, 57, 3622-3630. [CrossRef]

9. Lee, K.C.; Lee, H.H. Network-based fire-detection system via controller area network for smart home automation. IEEE Trans. Consum. Electron. 2004, 50, 1093-1100.

10. Electrical4u. Light Dependent Resistor. Available online: http://www.electrical4u.com/light-dependentresistor-ldr-working-principle-of-ldr/ (accessed on 14 September 2018).

11. Wiki.eprolabs. IR Obstacle Sensor. Available online: https://wiki.eprolabs.com/index.php?title=IR Obstacle_Sensor/ (accessed on 14 September 2018).

12. Louis, L. Working principle of arduino and using it as a tool for study and research. Int. J. Control Autom. Commun. Syst. 2016, 1, 21-29.

13. Arduino. Arduino Uno. Available online: https://store.arduino.cc/usa/arduino-uno-rev3/ (accessed on 14 September 2018).

14. Salvi, R.; Margaj, S.; Mate, K.; Aher, P.B. Smart street light using arduino uno microcontroller. Int. J. Innov. Res. Comput. Commun. Eng. 2017, 5, 5203-5206.

15. Cynthia, P.C.; Raj, V.A.; George, S.T. Automatic street light control based on vehicle detection using arduino for power saving applications. Int. J. Electron. Electr. Comput. Syst. 2017, 6, 291-295.

16. Bapat, M.; Ghotekar, S. Intelligent street light control management system using arduino. Int. J. Adv. Sci. Res. 2018, 3, 34-38.

17. Jalan, A.S. A survey on automatic street lightning system on indian streets using Arduino. Int. J. Innov. Res. Sci. Eng. Technol. 2017, 6, 4139-4144.

18. Mishra, S.; Gupta, S.; Singh, S.; Tiwari, T.; Mohan, A. Arduino based led street light auto intensity control system. Int. J. Adv. Res. Eng. Technol. Sci. 2016, 3, 73-77.

19. Rath, K. Arduino based: Smart light control system. Int. J. Eng. Res. Gen. Sci. 2016, 4, 784-790.

20. Jadhav, K.; More, A.; Rakshe, S.; Shinde, P.; Arya, C.S. Automatic street light control system. Imp. J. Interdiscip. Res. 2017, 3, 75-79.

21. Patil, A.N.; Tripathi, A.; Fanan, S.A. Intelligent street-light system using arduino uno. Int. J. Eng. Sci. Comput. 2017, 7, 10919-10922.

22. Gowdhaman, T.; Scholar, P. Automatic street light control and fault detection system with cloud storage. Int. J. Sci. Eng. Res. 2017, 8, 1-5.

23. Keni, P.; Wajid, S.M.; Ahmad, S.Z.; Rahimunnisa, K.S. Automated street lighting system using IoT. Int. J. Adv. Res. Ideas Innov. Technol. 2018, 4, 1970-1973.

24. Rawal, J.; Patel, D.R.B. Wireless smart street light control. Int. J. Sci. Res. 2017, 6, 648-650.

25. Satyaseel, H.; Sahu, G.; Agarwal, M.; Priya, J. Light intensity monitoring and automation of street light control by Iot. Int. J. Innov. Adv. Comput. Sci. 2017, 6, 34-40.

26. Jalan, A.; Hoge, G.; Banaitkar, S.; Adam, S. Campus automation using Arduino. Int. J. Adv. Res. Electr. Electron. Instrum. Eng. 2017, 6, 4635-4642. 
27. Rao, A.; Konnur, A. Street light automation system using arduino uno. Int. J. Innov. Res. Comput. Commun. Eng. 2017, 5, 16499-16507.

28. Khachane, M.Y. Intelligent street lighting system. Int. J. Eng. Res. Comput. Sci. Eng. 2018, 5, 587-590.

29. Sharath, P.G.S.; Rudresh, S.M.; Kallendrachari, K.; Kumar, M.K.; Vani, H.V. Design and implementation of automatic street light control using sensors and solar panel. Int. J. Eng. Res. Appl. 2015, 5, 97-100.

30. Ramli, N.L.; Yamin, N.M.; Ghani, S.A.; Saad, N.M.; Sharif, S.A.M. Implementation of passive infrared sensor in street lighting automation system. ARPN J. Eng. Appl. Sci. 2015, 10, 17120-17126.

31. Sravani, A.; Malarvezhi, P.; Dayana, R. Design and implementation of dimmer based smart street lighting system using raspberry pi and IoT. Int. J. Eng. Technol. 2018, 7, 524-528. [CrossRef]

32. Thapa, C.; Rasaily, D.; Wangchuk, T.R.; Pradhan, A.; Ashraf, A. Auto intensity control of street light with solar tracker using microcontroller. Int. J. Eng. Trends Technol. 2016, 33, 369-372. [CrossRef]

33. Banerjee, R. Solar tracking system. Int. J. Sci. Res. Publ. 2015, 5, 1-7.

34. Rajasekhar, T.; Rao, K.P. Solar powered led street light with auto intensity control. Int. J. Tech. Innov. Mod. Eng. Sci. 2017, 3, 1-4.

35. Patel, B.B.; Kinjal, P.; Vinnie, G.; Deval, P. Solar smart led street lighting system. Int. J. Adv. Eng. Res. Dev. 2015, 2, 1277-1282.

36. Srikanth, M.; Sudhakar, K.N. Zigbee based remote control automatic street light system. Int. J. Eng. Sci. Comput. 2014, 639-643.

37. Prakash, B.; Reddy, G.K.; Geethika, A.; Reddy, B.S. IoT based monitoring and control system for home automation. Int. J. Res. 2018, 5, 4120-4124.

38. Nirosha, K.; Sri, B.D.; Mamatha, C.; Dhanalaxmi, B. Automatic street lights on/off application using IoT. Int. J. Mech. Eng. Technol. 2017, 8, 38-47.

39. Gupta, V.; Thakur, K.; Surnar, S.; Thakur, R. Iot based smart street lights. Int. J. Res. 2015, 2, $270-272$.

40. Arkade, S.; Mohite, A.; Joshi, S.; Sonawane, R.; Patil, V. IoT based street lights for smart city. Int. J. Res. Appl. Sci. Eng. Technol. 2016, 4, 178-181.

41. Gajare, M.P.; Deshpande, A.; Aulwar, L.; Deshmukh, S. IoT based streetlight automation system. Int. J. Eng. Res. Technol. 2017, 6, 831-833.

42. Kokilavani, M.; Malathi, A. Smart street lighting system using IoT. Int. J. Adv. Res. Appl. Sci. Technol. 2017, 3, 8-11.

43. Bhosale, S.; Gaware, K.; Phalke, P.; Wadekar, D.; Ahire, P. IoT based dynamic control of street lights for smart city. Int. Res. J. Eng. Technol. 2017, 4, 1181-1183.

44. Fraga, L.P.; Suárez, A.M.; Fernández, C.T.M.; Castedo, L.; González, L.M. A Review on Internet of Things for Defense and Public Safety. Sensors 2016, 16, 1644. [CrossRef] [PubMed]

45. Chunjiang, Y. Development of a smart home control system based on mobile internet technology. Int. J. Smart Home 2016, 10, 293-300. [CrossRef]

46. Zanella, A.; Bui, N.; Castellani, A.; Vangelista, L.; Zorzi, M. Internet of things for smart cities. IEEE Internet Things J. 2014, 1, 22-32. [CrossRef]

47. Stojkoska, B.R.; Trivodaliev, K.; Davcev, D. Internet of things framework for home care systems. Wirel. Commun. Mob. Comput. 2017, 2017, 8323646. [CrossRef]

48. Akinyemi1, L.A.; Shoewu, O.O.; Makanjuola, N.T.; Ajasa, A.A.; Folorunso, C.O. Design and development of an automated home control system using mobile phone. World J. Control Sci. Eng. 2014, 2, 6-11.

49. Sriskanthan, N.; Tan, K. Bluetooth based home automation systems. J. Microprocess. Microsyst. 2002, 26, 281-289. [CrossRef]

50. Sivakrishnan, J.; Vigneswaran, E.E.; Vishnu, R.S. Home automation control and monitoring system using BLE device. Middle-East J. Sci. Res. 2016, 24, 78-82.

51. Led Supply. 5mm LED. Available online: https://www.ledsupply.com/blog/how-does-a-5mm-led-work/ (accessed on 14 September 2018).

52. Explain That Stuff. Resistors. Available online: https://www.explainthatstuff.com/resistors.html (accessed on 14 September 2018).

53. How to Mechatronics. L298 Motor Module. Available online: https://howtomechatronics.com/tutorials/ arduino/arduino-dc-motor-control-tutorial-1298n-pwm-h-bridge/ (accessed on 14 September 2018).

54. Electronics Hub. IR Sensor. Available online: https://www.electronicshub.org/ir-sensor/ (accessed on 14 September 2018). 
55. Maker Pro. Use an LDR Sensor. Available online: https://maker.pro/arduino/tutorial/how-to-use-an-ldrsensor-with-arduino/ (accessed on 14 September 2018).

56. Arduino. Arduino Mega. Available online: https://www.arduino.cc/en/pmwiki.php?n=Main/ arduinoBoardMega/ (accessed on 14 September 2018).

57. Mikhaylov, K.; Plevritakis, N.; Tervonen, J. Performance analysis and comparison of bluetooth low energy with ieee 802.15.4 and simpliciti. J. Sens. Actuator Netw. 2013, 2, 589-613. [CrossRef]

58. Keyence. Ultrasonic Sensor. Available online: https://www.keyence.com/ss/products/sensor/ sensorbasics/ultrasonic/info/ (accessed on 14 September 2018).

59. Adafruit. IR Distance Sensor. Available online: https://www.adafruit.com/product/1568/ (accessed on 14 September 2018).

60. All about Circuits. An Introduction to Laser Diodes. Available online: https://www.allaboutcircuits.com/ technical-articles / an-introduction-to-laser-diodes / (accessed on 14 September 2018).

(C) 2018 by the authors. Licensee MDPI, Basel, Switzerland. This article is an open access article distributed under the terms and conditions of the Creative Commons Attribution (CC BY) license (http:/ / creativecommons.org/licenses/by/4.0/). 